\title{
A perspective on orchid seed and protocorm development
}

\author{
Edward C. Yeung ${ }^{*}$ (1)
}

\begin{abstract}
This perspective draws attention to the functional organization of orchid seed and protocorm during the course of development. The orchid embryos have a well-organized developmental plan generating a blue-print of a protocorm as they mature. The different phases of embryo development in orchids, i.e. histodifferentiation, storage product synthesis and accumulation, and maturation are essentially similar to other flowering plants. The protocorm is considered as a unique structure designed to establish symbiotic association with mycorrhizal fungi and with the primary goal to form a shoot apical meristem. This perspective brings forth arguments that the processes of embryo and protocorm development are highly programmed events, enhancing survival of orchid seeds and plantlets in their natural habitats. Furthermore, the ability of protocorm cells to divide, makes them ideal explants for micropropagation and transformation studies. Through seed germination and micropropagation using protocorms as explants, orchid conservation efforts are greatly enhanced.
\end{abstract}

Keywords: Embryo, Suspensor, Endosperm, Seed coat, Protocorm, Phytohormones, Shoot apical meristem, Regeneration, Protocorm-like bodies, Orchid mycorrhizae, Micropropagation

\section{Background}

An understanding of plant reproductive biology is essential to plant conservation efforts. In orchids, after a successful pollination event, numerous seeds are produced within a single capsule. Utilizing seeds through asymbiotic and symbiotic seed germination for plant maintenance and propagation are key approaches in orchid conservation efforts. In order to further optimize current methodologies on seed germination and plantlet establishment, we need to have a proper understanding of seed biology, as well as the structure and function of protocorm.

Key features of orchid embryos, seeds, and protocorms are summarized in this article. The globular-shape and small sizes of orchid embryos imply that the embryos are simple and not as well developed as in other flowering plants. On the contrary, the author sees that orchid embryos have developed a plan, generating a blue-print of a protocorm as they mature. The different phases of

*Correspondence: yeung@ucalgary.ca Department of Biological Sciences, University of Calgary, Calgary, ABT2N 1N4, Canada embryo development in orchids, i.e. histodifferentiation, storage product accumulation, and maturation are essentially similar to other flowering plants. The protocorm formed at the time of seed germination is considered as a unique structure designed to establish symbiotic association with mycorrhizal fungi and with the primary goal to form a shoot apical meristem. This perspective brings forth arguments that the process of embryo and protocorm formation involves highly programmed events, enhancing survival of orchid seeds and plantlets in their natural habitats. The intent of this article is to generate additional interests, discussions, and further studies on orchid seed biology in the near future.

\section{Embryo development}

The zygote and the proembryo

In flowering plants, a successful fertilization event results in seed formation in which an ovule becomes a seed, the egg cell becomes a zygote, the central cell forms the endosperm, and the integuments develop into the seed coat. Detailed accounts on changes of the egg cell before and after fertilization about orchids are few. In Epidendrum scutella, after fertilization, the size of the zygote is 
similar to the egg cell and there is little change to the vacuolar system within its cytoplasm (Cocucci and Jensen 1969). Rough endoplasmic reticulum and polysomes become more abundant, indicating an increase in metabolic activities within the cell. It is interesting to note that dictyosomes could not be detected in the zygote after fertilization (Cocucci and Jensen 1969). At the light microscopic level, the zygote maintains a uniform dense cytoplasm, e.g. Cymbidium sinense (Yeung et al. 1996) and Calypso bulbosa (Yeung and Law 1992), or it can have a polarized appearance with a distinct vacuole(s) located at the micropylar end such as in Cypripedium passerinum (Law and Yeung 1993) and Phaius tankervilliae (Ye et al. 1997). The phenomenon of 'zygote shrinkage' (see Natesh and Rau 1984) prior to the first zygote mitosis appears to be absent. Changes in microtubule cytoskeleton have been noted, reflecting dynamic changes within the zygote prior to its first mitotic division. Soon after zygote formation, the microtubules are randomly arranged. As the zygote increases in size, the microtubules organize into a meshwork in the cytoplasm and a dense array of microtubules begins to appear in the cortical region near the chalazal pole (Huang et al. 1998). Moreover, additional studies are needed to decipher cellular events leading to the establishment of cell polarity within the zygote at this critical stage of development.

In the zygote, varying degree of vacuolation appears within its cytoplasm. In C. bulbosa (Yeung and Law 1992) and C. sinense (Yeung et al. 1996) the cytoplasm of the zygote remains dense through the first mitotic division. In these examples, the first zygote division is usually symmetrical or slightly asymmetrical in appearance. For orchids having a polarized zygote with large vacuole(s) located at the micropylar end of the cell, such as those found in C. passerinum (Law and Yeung 1993) and Phaius tankervilliae (Ye et al. 1997), the first division is asymmetrical giving rise to two cells of unequal sizes. Changes to the orientation and distribution of the microtubule cytoskeleton are observed at this time (Huang et al. 1998). Irrespective of the cell division symmetry, cell division results in the formation of a terminal and a basal cell, each having a distinct fate. The basal cell can differentiate into a short-lived embryonic organ, known as the suspensor, and the terminal cell will give rise to the embryo proper.

One of the key events occurring after zygote division is the establishment of a polarized embryo axis leading to cell fate determination and the formation of a body plan (Ueda and Laux 2012; Wabnik et al. 2013). Such information similar to the study of Arabidopsis is lacking in orchids. The oblique divisions observed in the formation of the proembryo in C. sinense (Yeung et al. 1996), the changes in microtubule organization (Huang et al. 1998), the varied patterns of suspensor formation, and limited number of cells in the embryo proper, suggest new regulatory controls in proembryo establishment in orchid.

Based on the cell division pattern in the zygote and proembryo, as well as the varied forms of suspensor morphologies, different embryo types were proposed (Swamy 1949; Johansen 1950). Moreover, the suggested embryological system of classification sees limited use by embryologists. More recently, Clements (1999) provided a more extensive description of embryo developmental types, incorporating the classification system proposed by Dressler (1993).

\section{The suspensor}

The different morphologies of the suspensor within Orchidaceae generate a lot of interest in the study of embryo development (see Yam et al. 2002). The suspensor can appear as a single cell, highly elongated haustorial structures, or multicellular swollen forms that fill the embryo cavity (Swamy 1949). What directs the growth and morphogenesis of the varied suspensor forms? In the study of the nun orchid suspensor development, cytoskeletal elements, i.e. microtubules and microfilaments, play an important role in suspensor morphogenesis (Ye et al. 1997), especially in the elongation of suspensor cells. Dynamic changes in the microtubule cytoskeleton are also observed in C. sinense during the course of suspensor formation and elongation (Huang et al. 1998). However, other extrinsic and intrinsic signals regulating suspensor development are not known at present.

With the small size of the embryo proper and the lack of an endosperm, it is logical to speculate that the varied forms of suspensors can play important roles in nutrient uptake. Histochemical staining of cell walls indirectly supports the notion that orchid suspensor can serve as a nutrient uptake site. The polychromatic stain toluidine blue $\mathrm{O}$ (TBO) can distinguish lignin, cellulose, and pectic substances on the basis of color differences (O'Brien et al. 1964; Feder and O'Brien 1968; O'Brien and McCully 1981). The fact that the suspensor cell wall stains pinkish-purple with no detectable lignin and cutin deposits, suggests that water and water soluble substances should be able to move apoplastically from the seed coat to the developing embryo proper via suspensor cells (Lee and Yeung 2010). The pinkish-purple color of the suspensor wall after TBO stain also suggests the presence of negatively charged groups which can increase cation-binding capacity of a wall (Smith 1972), and this can aid in solute uptake. A simple plasmolysis experiment indicates that the suspensor cell in the nun orchid has a more negative osmotic potential than the surrounding seed coat cells (Lee and Yeung 2010). The negative osmotic potential 
provides a driving force for water uptake by the suspensor. In order to visualize the uptake pathway, a fluorescent tracer 6-carboxyfluorescein diacetate (CFD) was applied to developing seeds. Once taken up by the cell, CFD would be hydrolyzed to carboxyfluorescein, giving a fluorescence signal within the cytoplasm. In this experiment, the fluorescence signal was first detected in the suspensor cell before appearing in the embryo proper (Lee and Yeung 2010). This work clearly demonstrates the pathway of solute movement and the importance of suspensor in embryo nutrition.

In flowering plants, the suspensor can take on structural and biochemical specializations (Yeung and Meinke 1993; Kawashima and Goldberg 2010). Transfer cell morphology is one of the common structural specializations observed in suspensor cells. In Paphiopedilum delenatii, wall ingrowths are found in suspensor cells (Lee et al. 2006). Wall ingrowths increase the surface area of a cell which can aid in short distance transport. Hence, the formation of wall ingrowths further strengthens the notion that orchid suspensor is specialized in nutrient uptake. The membrane associated with wall ingrowths is unique, e.g. with a higher density of proton pumps (Bouché-Pillon et al. 1994). Future studies demonstrating the presence of biochemical specialization(s) will serve as proof of orchid suspensor function.

In Phaseolus species, having large suspensors, high quantities of different phytohormones have been detected (see Yeung and Meinke 1993; Kawashima and Goldberg 2010). Although orchid suspensor is small, it may have a similar biosynthetic ability. If this is true, the orchid suspensor will have additional roles to play during embryogenesis.

Not all orchids have a well-developed suspensor (see Swamy 1949; Clements 1999). In genera such as Spiranthes, many species are considered to be suspensorless. At present, the nutrient uptake pathway by these embryos is not known. In the absence of a suspensor, it is logical to speculate that the entire surface of the embryo proper must be able to absorb nutrients directly from surrounding maternal tissues, i.e. the seed coat. In Cyrtosia javanica, the seed coat is multilayered and the cells maintain their cytoplasm until seed maturation (Yang and Lee 2014). Furthermore, dense cytoplasmic accessory and antipodal cells are present, locating at the chalazal end of the seed coat, near the developing embryo (Yang and Lee 2014). Can these cells function like the haustoria-type suspensor cells by 'extracting' nutrients from the seed coat and further supply them to the developing embryo? In flowering plant, a cuticle is present on the surface of the embryo proper (Rodkiewicz et al. 1994; Lackie and Yeung 1996) and this can impede diffusion of nutrients into the embryo. Moreover, in C. javanica, the cuticle has a patchy appearance and it is initially absent from the walls at the chalazal end (Yang and Lee 2014). These structural features indicate that the $C$. javanica embryo is capable of nutrient uptake, especially at the chalazal end near the accessory and antipodal cells. In order to determine how nutrients enter the embryo in the absence of a suspensor, it is necessary to study the microenvironment surrounding the developing embryo and to perform tracer experiments similar to the study for the nun orchid.

\section{The embryo proper}

The pattern of embryo development in flowering plants can be divided into several phases (Goldberg et al. 1994). Once the polar axis is established with the formation of the proembryo, histodifferentiation begins with the formation of a shoot and a root apical meristems, the primary meristems (protoderm, ground meristem, and procambium), and the cotyledon(s). Upon the completion of the histodifferentiation phase, storage product synthesis and accumulation begins within embryo cells. Concomitant with storage product accumulation, the maturation phase sets in and the embryo will acquire desiccation tolerance and prepares for developmental arrest and germination events. This pattern of development contributes to the success and survival of flowering plants in the natural habitats. In lower vascular plants such as bryophytes and ferns, once the histodifferentiation phase is completed, the embryo will germinate immediately without a resting phase, as they do not have the ability to undergo storage product biosynthesis and developmental arrest. Moreover, in flowering plants, given the right conditions, developing embryo can also precociously germinate (Raghavan 1997) after the completion of the histodifferentiation phase, as the embryo has already established a functional body plan ready for germination.

Structural descriptions of mature orchid embryos are detailed by Yam et al. (2002). The number of cells and embryo sizes vary among species of Orchidaceae. Only 8 cells were reported for Epipogium aphyllum and approximately 700 cells for Bletilla striata (see Yam et al. 2002). The mature B. striata embryo appears to be one of the largest in the orchid family. Does histodifferentiation occur within a tiny orchid embryo proper? Although there is no obvious tissue pattern formed, histodifferentiation can still be identified (Vinogradova and Andronova 2002). The following discussion argues that histodifferentiation is an integral and a key step during early embryogeny. In orchid embryos, a gradient of cell size is often recognized with smaller cells located at the apical (chalazal) end and larger cells located at the basal (micropylar) end of the embryo. This represents the existence of 
a structural polarity. The cells at the apical pole of the embryo are destined to form a meristematic zone and the basal cells are designed to house the symbiont upon seed germination. Since the small and large cells have distinct cell fate upon seed germination, a physiological polarity must also be present within the embryo prior to seed germination. It is interesting to note that for easy-to-germinate species such as Phalaenopsis amabilis, a marked gradient of cell size exists within the embryo (Lee et al. 2008). This is in contrast to the difficult-to-germinate species such as C. bulbosa in which there is no marked difference in cell size (Yeung and Law 1992). Another indication of histodifferentiation is the formation a protoderm. Judging from the uniform cell profile of the surface layer, the embryo proper has acquired protoderm characteristics. A cuticle is found to envelop the embryo proper such as in C. sinense (Yeung et al. 1996) and $P$. delenatii (Lee et al. 2006). The ability to form a cuticle is an indication that the surface cells have acquired epidermal cell characteristics. The best argument that histodifferentiation has indeed occurred in an orchid embryo is that 'immature' orchid seeds can germinate asymbiotically in vitro, in a simple medium as long as sucrose is present (Knudson 1922). The orchid embryo has to establish a protocorm body plan during early embryogeny, in order to germinate precociously.

In orchids, the embryo is small with a reduced number of cells. Mitotic activities are arrested early. One can encounter mitotic figures readily within the embryo proper mainly soon after fertilization. Since the embryo proper has few cells, especially when compared to other flowering plants, this suggests that the rate of cell division is slow and/or the cells have a long cell cycle time. A recent study on the expression patterns of the cell-cycle genes in Phalaenopsis aphrodite indicates that genes are coordinately regulated from ovule development to embryogenesis (Lin et al. 2014). It would be interesting to determine the intrinsic factors within the embryo which regulate the cell cycle program and mitotic activity as embryo develops.

The absence of a cotyledon is a common characteristic of orchid species. Not more than 10 species have been reported to have a small protrusion that appears to be a rudimentary cotyledon (see Nishimura 1991). In a majority of cases, the protrusions fail to develop further in a protocorm and appear to have no contribution to protocorm development (Nishimura 1991). Bletilla striata has the most distinct protrusion at the apical end of the embryo; can this protrusion be considered a cotyledon? It is important to note that B. striata has one of the largest embryos in Orchidaceae (Yam et al. 2002). Judging from scanning electron micrographs, the expanding rudimentary cotyledon of $B$. striata closely encircles the developing shoot apical meristem (SAM) (see Figs. 4-12 in Vinogradova and Andronova 2002). Unlike other orchid protocorms, an expanded meristematic zone is not present prior to SAM formation. The close physical proximity between the protrusion and the SAM suggests that it might be a cotyledon. As shown in Arabidopsis embryo development, the SAM and cotyledons are formed at the time during histodifferentiation (Laux et al. 2004). If SAM cells or cells having SAM characteristics can be demonstrated in B. striata embryo during embryogeny, the protrusion should be regarded as a cotyledon. Future molecular genetics studies on embryo development will provide new insight into the identity of B. striata cotyledon-like protrusion and why cotyledons are absent in Orchidaceae.

In flowering plants, storage product deposition begins soon after the completion of the histodifferentiation phase. In dicots such as canola and Arabidopsis, the embryo proper begins to expand and fills the endosperm cavity and mitotic activities soon subside. This is followed by the appearance of starch deposits. Starch granules are subsequently replaced by the formation of storage protein and lipid bodies. In orchids, a similar pattern is observed. In C. sinense (Yeung et al. 1996), starch granules first appear within the cytoplasm. The large vacuoles are gradually replaced by small ones and storage protein and lipid bodies begin to appear. In a mature orchid embryo, there are abundant storage protein and lipid deposits; starch granules are rare. Besides histological studies, little is known about the physiology of storage product deposition and how storage products influence germination behavior and long term seed storability (Schwallier et al. 2011; Colville et al. 2016). In canola microspore-derived embryos, abscisic acid (ABA) has been shown to induce lipid and oleosin biosynthesis (Zou et al. 1995). ABA levels begin to increase in Cypripedium formosanum (Lee et al. 2015) approximately at the same time of storage product accumulation, indicating that $\mathrm{ABA}$ can play a role in storage product deposition in orchids.

Are there sufficient storage reserves to sustain seed germination? Orchid embryos though small, have cells packed with storage products. In their natural habitat, it has been reported that the storage products, especially lipid reserves are not utilized unless mycorrhizal establishment has initiated. Harrison (1977) suggested that "this slow expenditure of reserve metabolites could permit the orchid seedling to survive for a longer period until an appropriate endophytic infection is established". In Arabidopsis, ABA levels can influence availability of energy and nutrients in seeds during germination (Garciarrubio et al. 1997). A high level of ABA can prevent the breakdown of storage proteins (Garciarrubio et al. 1997) and lipids (Graham 2008). 
The final stage of embryo development is considered as the maturation phase. Seeds need to be desiccation resistant in order to survive the natural environment. Recent evidence indicates that a desiccation period is necessary, preparing seeds for subsequent germination (Holdsworth et al. 2008; Angelovici et al. 2011). In P. amabilis hybrids, the decline in relative water content between 150 and 165 day after pollination coincides with the acquisition of desiccation tolerance (Schwallier et al. 2011). The presence of high levels of ABA in mature orchid seeds may be essential for the acquisition of desiccation tolerance, as demonstrated in the study of alfalfa seeds (Xu and Bewley 1995). In order to respond to potential abiotic stresses, a common biochemical marker, the late embryogenesis abundant (LEA) proteins, are shown to accumulate at the time of seed maturation in Dendrobium officinale (Ling et al. 2016). The presence of long lived mRNAs in mature seeds is a well-documented phenomenon in many flowering plants (Dure 1979, 1985; Sano et al. 2012). Recent proteomic analyses in rice indicated the upregulation of 20 proteins even in the presence of a transcription inhibitor, actinomycin $\mathrm{D}$, indicating that long lived mRNAs must be present in mature seeds (Sano et al. 2012). In Spathoglotis plicata, Raghavan and Goh (1994) used the ${ }^{3} \mathrm{H}$-poly-(U) in situ hybridization method to demonstrate that poly(A)-RNAs are present and uniformly distributed throughout the mature embryo. This study indicates the potential presence of long-lived mRNAs in mature embryo cells. Future proteomic analysis, similar to that performed in rice, may enable the identification of proteins essential to early stages of germination. From the available information, preparations during seed maturation in orchids appear to be similar to other flowering plants.

The tiny orchid embryo is often described as "globular", implying that orchid embryo is poorly developed and organized when compare to embryos of other flowering plants. Judging from the cell arrangement and their ability to form protocorms upon germination, histodifferentiation has occurred and the 'protocorm body plan' is laid down ready for germination. As seeds mature, additional changes have taken place in preparation for developmental arrest and subsequent germination events. Therefore, one should consider that the pattern of embryo development in orchids is similar to that of other flowering plants; not simple, nor primitive.

\section{The endosperm}

Yam et al. (2002) provided a detailed account summarizing the presence, absence and/or development of an endosperm in orchid embryos. Although some degrees of endosperm development, i.e. with a multinucleate stage in some species (Yam et al. 2002), continual development similar to other flowering plants is absent. The failure to form a functional endosperm is one of the distinctive features in orchid seed development. Why does endosperm formation fail? Anomalous development in the ovules and/or the male gametes can contribute to endosperm failure in orchids. The formation of the central cell in an embryo sac is complex (Lopez-Villalobos et al. 2016). The competition for nutrients among numerous ovules, may have a negative effect on central cell development. Is the reduction in the number of nuclei present within an embryo sac, commonly referred as the 'striking phenomenon' (Yeung and Law 1997; Batygina et al. 2003), an early indication of central cell abnormality? In E. scutella, the polar nuclei fuse before fertilization; however, fusion is not complete (Cocucci and Jensen 1969). In C. sinense a microtubular network can be found in the cortex of the endosperm cell up to the four-cell stage of embryo development; however, microtubules are not found to be associated with the nuclei present (Huang et al. 1998). The lack of a functional cytoskeletal network may be partially responsible for the absence of mitotic activities within the endosperm cell.

Can the male gametes contribute to endosperm failure? In E. scutella, once the sperm nucleus enters the central cell, the chromatin appears less dense in the embryo sac than in the pollen tube (Cocucci and Jensen 1969). In the nun orchid, the gamete nucleus that fuses with the polar nuclei of the central cell also has a lower staining intensity, prior to fertilization (Ye et al. 2002). Gamete dimorphism has been reported in sperm cells of a number of species such as tobacco late in sperm development (Tian et al. 2001). Preferential fertilization of one of the sperm cells with the egg has been noted. In Plumbago zeylanica, the plastid-rich, mitochondrion-poor sperm cell tends to fuse with the egg cell (Russell 1985) and a preferential transmission of supernumerary B chromosomes to the egg cells during sexual reproduction in maize has been reported (see Weterings and Russell 2004). Although gamete dimorphism is not a universal phenomenon in flowering plants, if there is defect in the male gamete destined for the central cell, endosperm development could fail. In orchids, since a massive number of pollen tubes is present within a capsule prior to fertilization, this is an excellent experimental system to study sperm cell structure and function and the results can provide clues as to whether the male gametes can contribute to endosperm failure in orchids.

A varied number of nuclei is present within the primary endosperm cell after fertilization. The origin of these nuclei has generated a lot of discussion. The nuclei within the endosperm cell can represent unfused nuclei from the central cell together with one of the gamete nuclei, or as mitotic products of the primary endosperm 
nucleus after fertilization. It is generally agreed that there is no fusion of nuclei within the central cell and the nuclei soon degenerate within the primary endosperm cell as the embryo begins to develop. In Vanilla planifolia, Swamy (1947) reported the formation of a primary endosperm nucleus and having several rounds of division prior to degeneration; however, a recent study by Kodahl et al. (2015) indicated that such a process did not occur. It is also possible that "remnants of the primary chalazal nuclei persist in the organized embryo sac" as in Epipogium roseum (Arekal and Karanth 1981), contributing to the confusion of nuclear number within the primary endosperm cell. Even with improved optical instrumentation, the origin of various nuclei is difficult to determine. To confirm that the nuclei observed are indeed originated from the primary endosperm nucleus, one needs to clearly demonstrate the presence of mitotic figures within the primary endosperm cell.

The lack of a functional endosperm may be the cause of "tiny" embryo formation. In the majority of flowering plants, after fertilization, endosperm develops rapidly aiding in seed enlargement. The endosperm also serves as a nutrient depot and is also a rich source of phytohormones such as gibberellins and cytokinins. All these factors can promote and regulate embryo development (Lopes and Larkins 1993). In the absence of an endosperm, the orchid embryo cannot expand and hence remains small.

In general, when the endosperm fails to develop, the embryo also aborts (see Vijayaraghavan and Prabhakar 1984). The fact that the orchid embryo continues to develop and survive without the presence of an endosperm indicates modifications to the embryo developmental program. The ability of the suspensor to acquire nutrients and the presence of a cuticle to prevent rapid desiccation, are possible strategies that enable continual embryo development in the absence of an endosperm. The ability of orchid embryos to develop without an endosperm, removes one of the potential barriers for hybrid failure (van der Pilj and Dodson 1966).

One can envisage that orchids have devised a new strategy in seed development during their evolution. Since the success of plantlet formation rests on the success of protocorms in establishing proper mycorrhizal interactions, endosperm formation is deemed unnecessary.

\section{Seed development-regulation by phytohormones}

Phytohormones play important roles in all aspects of plant growth and development. Similar to other flowering plants, phytohormones play important roles in orchids. In E. ibaguense, following pollination, changes in phytohormones are noted during fruit and seed development with a continual increase in cytokinin activity and a detectable gibberellin activity, indicating the involvements of phytohormones in orchid fruit and seed development (Taylor et al. 1982). At present, studies on phytohormones focusing on orchid reproductive development are few. More efforts are needed in the future.

\section{Auxin}

In orchids, auxin has been shown to play essential roles during pollination and early stages in fruit development (see Novak et al. 2014). Changes in ethylene and auxin are noted at the time of pollination in Phalaenopsis. Ethylene in the presence of auxin is required for initiating ovule development and pollen germination and growth (Zhang and O'Neill 1993). During protocorm development, polar auxin transport inhibitors can influence leaf formation and protocorm morphogenesis (Novak et al. 2014). Expression analysis of fertilization and early embryogenesis-associated genes in Phalaenopsis indicate that auxin and ethylene can play a role at the critical stage of seed formation (Chen et al. 2016). Although the precise action of auxin is not clear during seed development and germination, the information at hand indicates that auxin must has an important role to play.

\section{Cytokinins}

Cytokinins are essential to plant growth and development, especially in regulating mitotic activities (Emery and Atkins 2006). In E. ibaguense, an increase of cytokinin activity coincides with fertilization and commencement of embryo development (Taylor et al. 1982). Since by that time cell division in the fruit wall has more or less completed, the increase in cytokinin activity is most likely related to embryo development (Taylor et al. 1982). However, unlike the majority of flowering plants, cytokinin activity remains high throughout maturation. Is this a unique phenomenon common to orchids? Do the high levels of endogenous cytokinins play a role in seed germination? Many questions remain to be answered.

\section{Gibberellins}

In seeds such as cereals and legumes, major peaks of biologically active gibberellins are found during early seed development, and little activity can be detected as seeds mature (see Taylor et al. 1982). In E. ibaguense, although there is a gradual reduction in GA activities, a significant level can still be detected in mature seeds, similar to the pattern observed for cytokinin activity. Again, this begs the question as to whether gibberellins have a role to play during germination and protocorm development.

\section{Abscisic acid}

It is well documented that abscisic acid (ABA) plays important regulatory roles in different aspects of seed 
development such as storage product biosynthesis and seed dormancy (Nambara et al. 2010). Endogenous ABA has been reported by Van der Kinderen (1987) using chromatographic methods and by Lee et al. (2007b; 2015) using the technique of ELISA and immunostaining. In Cypripedium formosanum (Lee et al. 2015), ABA level remains low during early seed development and rises rapidly mid-way during seed maturation. The ABA level follows changes in water content suggesting changes in water content can serve as an endogenous signal for $A B A$ biosynthesis. The importance of $\mathrm{ABA}$ is clearly demonstrated experimentally through the use of the ABA biosynthesis inhibitor, fluoridone. Enhanced germination of mature seeds was noted after injecting fluoridine into developing seed capsules (Lee et al. 2015). For difficult to germinate species, the low percentage of seed germination is attributed to their endogenous ABA content (Van der Kinderen 1987). Lowering of ABA level through seed stratification and pre-treatment procedures prior to seed germination can enhance seed germination (Linden 1992). Hence, in vitro culture of immature seeds, prior to the increase in ABA level, improves successes to asymbiotic germination of orchid seeds.

\section{The physical environment surrounding the embryo}

Orchid seeds are small and dust-like, and can have a variety of surface features, i.e. smooth or sculptured. The seed is air-filled and houses an even smaller embryo. The physical properties of orchid seeds and the biological implications of various characteristics have been detailed in an extensive review by Arditti and Ghani (2000) and a summary of seed structures can be found in the monograph by Dressler (1993). The developmental features of seed coats are discussed by Molvray and Chase (1999) and Lee et al. (2007a).

Although orchid seeds are small, they have distinct seed coat features. In general, the seed coat is composed of a few layers of cells with no vascular tissue present, and it develops mainly from the outer integument of the ovule after fertilization. The inner integument tends to degenerate. Exceptions are noted as in the subfamily Vanilloideae; a number of species, e.g. Vanilla planifolia (Swamy 1947) and Cyrtosia javanica (Yang and Lee 2014) have a multi- layered seed coat and the outermost layer is heavily lignified. For the majority of orchid seeds, even though the seed coat is thin, the addition of secondary walls, phenolic substances, and cuticular materials offer additional protection to the embryo within.

The inner integument of the ovule usually fails to develop much further after fertilization, the cells often degenerate or collapse around the embryo proper forming a 'shell', termed as 'carapace' (Veyret 1969; also see Yam et al. 2002). In Dactyloriza majalis, a carapace is readily detected and it wraps tightly around the embryo (Rasmussen 1995). The carapace can offer further protection to the embryo. Additional deposition of phenolic compounds and cuticular materials further strengthens the carapace. The low percentage of mature seed germination observed in Cephalanthera falcata is attributed to the accumulation of substances such as lignin in the inner integument, a possible cause of germination inhibition (Yamazaki and Miyoshi 2006). In easy-to-germinate species such as Orchis morio and Serapias lingua, a carapace is incompletely formed around the embryo (Veyret 1969). In the natural environment, the presence of added protection from carapace may prolong seed survival, enhancing their chance of establishing mycorrhizae association with an appropriate symbiont. However, it can be one of the major causes in inhibiting germination of mature seeds in vitro.

\section{Knowledge of seed development aids in asymbiotic seed germination efforts}

The features discussed above enable orchid seeds to germinate symbiotically in their natural habitats. Moreover, features such as high ABA levels and the formation of a thick carapace with phenolic deposits will have negative impacts on asymbiotic seed germination. It is well established that selecting 'green' capsules at a certain time of fruit development increases the rate of asymbiotic seed germination. This phenomenon can now be explained by the fact that the embryo has completed the histodifferentiation program with the formation of a blue-print for protocorm formation. Also at this time, ABA level is low and only a thin cuticle is present around the embryo proper. Additional physical barriers such as a thick seed coat and carapace have not yet fully developed. All these features facilitate asymbiotic seed germination of immature seeds.

The accumulation of high levels of $\mathrm{ABA}$ and secondary metabolites are recognized as key negative factors in asymbiotic germination of mature seeds. Methods are now available to reduce the levels of inhibitory substances using solvents in conjunction with seed sterilization protocols (Kauth et al. 2008; Lee 2011). Additional methods, i.e. low temperature, including freezing (Rasmussen 1995; Mweetwa et al. 2008), and sonication (Miyoshi and Mii 1988) are some of the methods that can improve asymbiotic mature seed germination (see Lee and Yeung 2017).

Although successes are regularly reported in the literature, it is important to note that when comparing asymbiotic and symbiotic germination of the same species, the development of the protocorms and plantlets can differ (Vinogradova and Andronova 2002) and growth is usually better in the latter (Johnson et al. 2007). This 
indicates that current in vitro protocols and/or culture media still need to be improved and the conditions optimized.

\section{Protocorm}

Upon seed germination, the orchid embryo first develops into a protocorm before forming a plantlet. The term protocorm was introduced by Treub in 1890 to describe the early stages of in the germination of lycopods (Arditti 1992). Veyret (1974) and Vinogradova and Andronova (2002) gave detailed accounts on the varied forms of protocorms and plantlets in their extensive reviews.

From a developmental and functional point of view, orchid protocorm is a unique structure designed to establish symbiotic association with a compatible fungus, and with the primary goal to form a shoot apical meristem (SAM) for plantlet growth. The body plan of a protocorm is established during embryogeny, with cells having distinct cell fates. Hence the protocorm stage should not be considered as an extension of embryonic development. A recent molecular biology study also indicates that protocorms are molecularly distinct from zygotic embryonic tissues in Phaleaenopsis aphrodite (Fang et al. 2016). In order to avoid confusion in description, one should reframe from using the term 'embryo' when referring to a protocorm.

Upon placement on appropriate medium, the embryo within the seed coat begins to swell in size and becomes a protocorm. Cells at the apical end divide rapidly, while those at the basal end enlarge and increase their ploidy level during asymbiotic (see Chen et al. 2009) and symbiotic (Rasmussen 1990) germination. The early events in protocorm development are likely regulated by the preprogrammed long-lived mRNAs formed during seed maturation as indirectly demonstrated by Raghavan and Goh (1994). The unique properties of protocorms are further illustrated during symbiotic seed germination. Recent EST analysis in Dendrodium officinale reveals the involvement of putative genes (Zhao et al. 2013). Genes and proteins related to defence and stress response, metabolism, transcriptional regulation, transport process and signal transduction pathway are upregulated (Zhao et al. 2013; Valadares et al. 2014; López-Chávez et al. 2016). These studies indicate that the protocorm has the ability to response and prepare to interact with mycorrhizal fungi.

\section{Protocorm is prepared to receive its symbiont}

Fungal hyphae enter the imbibed embryos or developing protocorms at their basal end. For newly imbibed seeds, the degenerated suspensor appears to be the preferred site of hyphae entry (see Wright et al. 2005). Although the suspensor has degenerated, because its wall is primary in nature, penetration through the suspensor or nearby cells is ensured. The presence of the carapace and the cuticular covering of the embryo proper ensure that the apical protocorm cells are protected and not physically damage by the hyphae. For protocorms with more advanced development, i.e. with rhizoid formation, epidermal cells and rhizoids appear to be the preferred site of hyphae entry (see Wright et al. 2005). Stoutamire (1983) suggests that the trichomes may have a function to play in establishing mycorrhizal association.

In Caladenia tentaculata, the compatible fungal isolate always infects the seed through the suspensor, resulting in a successful mycorrhizal establishment in protocorms (Wright et al. 2005). In this orchid, phenolic material produced by the embryo diffuses towards its suspensor end; this substance may guide the hyphae towards the embryo. Pelotons appear within the enlarged basal cells of the protocorm and they are digested by protocorm cells at regular intervals for nutrients. For incompatible strains, fungal hyphae do not infect protocorms. They enter through rhizoids or other epidermal cells rather than through the degenerated suspensor. In this case, peloton fails to form and the protocorms are often destroyed by the fungal hyphae (Wright et al. 2005). Moreover, in Dactyloriza majalis, fungal hyphae have to enter the protocorm through rhizoids in order to be successful (Rasmussen 1990); entry of hyphae through the suspensor fails to establish mycorrhizal association.

The site of hyphae entry may have important consequences in the success or failure in establishing mycorrhizal association. Since some orchids are 'suspensorless' while others may have taken a longer time to germinate forming rhizoids, the subtle structural and physiological differences in protocorm development may determine which symbiont is best suited for a particular orchid. Do different mycorrhizal fungi have their own preferred site of entry into a protocorm in order to establish a successful interaction? When comparing in vitro vs. in situ studies, selectivity toward fungal symbionts differs for the same species (Masuhara and Katsuya 1994; see also Smith and Read 2008). Is that due to minor differences such as the presence or absence of rhizoids in protocorm development?

The ability to digest pelotons to obtain nutrient supplies is an important strategy in orchids in order to achieve successful plantlet formation. For mycotrophic orchids, nutrients have to come from the mycorrhizal fungi. A recent study by Fochi et al. (2017) demonstrated that a bidirectional nutrient transfer can occur between orchids and its symbionts. Future studies using combined techniques of molecular genetics, cell biology, biochemistry, and physiology will provide additional insights and possible mechanisms into nutrient transfer 
between them. Besides contributing nutrient supplies to the orchid host, mycorrhizal fungi are known to produce phytohormones (Liu et al. 2010). Can they contribute to morphogenesis and subsequent plantlet formation of protocorms through phytohormone supplies? Although there are still many unanswered questions, the above examples highlight the unique properties of protocorms and the process of mycorrhizal establishment and their interactions.

\section{The ultimate goal of a protocorm is to form a shoot apical meristem (SAM)}

Meristems make the plants (Sussex 1989). Without a functional SAM, there is no further development into a plantlet. Figure 1a-i detail SAM formation in E. ibaguense. The embryo at the time of germination has a dense cytoplasm, especially at the future shoot pole. Protein bodies are abundant at this time (Fig. 1a). Within $96 \mathrm{~h}$ of germination, storage products are mobilized and judging from the cell profiles, mitotic activities have initiated (Fig. 1b). In Spathoglottis plicata, active mitotic activities can be found in the apical pole of the protocorm as early as 4 days after sowing (Raghavan and Goh 1994). With the disappearance of storage products, plastids become abundant within protocorm cells and starch granules are readily detected within plastids (Fig. 1c). The cells at the shoot pole remain small and have similar cytological features (Fig. 1c). Soon after, for cells that are destined to form the future SAM initials, they are characterized by having a large nucleus to cytoplasm ratio (Fig. 1d). The shoot apical meristem initials soon become more distinct as cells begin to take on a square to angular shape and starch granules are not as abundant as surrounding cells (Fig. 1e). These cytological features clearly mark the initiation of a SAM.

The next event is the formation of the first leaf primordium. The apical meristem zone first broadens and in the peripheral region, cells forming the first leaf primordium begin to enlarge (Fig. 1f) and as a result, a leaf primordium begins to protrude above the surface (Fig. 1g-i). This results in generating a small depression with the SAM cells located at the center of the depression (Fig. 1g, h). The 'dimple'-shaped apex has been reported in the literature, e.g. see figures in Leroux et al. (1997) and Vinogradova and Andronova (2002). The SAM continues to mature and increase in size and becomes a dome-shaped structure, initiating leaf primordia at regular intervals (Fig. 1i). It is only after the formation of a well-defined SAM, adventitious roots begin to form near the SAM endogenously.

The nature and origin of the protrusion from a protocorm is a subject of discussion (Vinogradova and Andronova 2002; Batygina et al. 2003; Yam et al. 2002).
Should it be considered as a cotyledon or a leaf? Since a protocorm is a post-embryonic structure, the initial leaf-like protrusion formed at the protocorm stage cannot be regarded as cotyledons (Batygina and Andronova 2000). As shown in Fig. 1, the initiation of the first leaf primordium takes place after the formation of a SAM in its peripheral region, even though the SAM has not yet taken on a mature domed-shaped structure.

Although one can pin-point the location of a SAM in the protocorm, the molecular genetics involve in SAM initiation are not known. In Arabidopsis, SAM genes such as WUSCHEL and CLAVATA3 are expressed early at the histodifferentiation stage (Laux et al. 2004). The importance of WUS in meristem formation and function is well established. In monocot species, such as corn and rice, the orthologues of WUS appear to be regulated differently from Arabidopsis (Nardmann and Werr 2006). What are the genes involved in SAM formation in orchid protocorm? Do SAM genes regulated differently from the rest of the flowering plants? To truly understand the origin of a SAM and the nature of the first leaf primordium, additional detailed cellular and molecular genetic studies are needed. Many important questions still need to be answered.

\section{When does the protocorm stage end and plantlet stage begin?}

Although the formation of a protocorm leading to plantlet formation is a continuous developmental process, for the ease of description and discussion between studies, the author would like to suggest that protocorm stage ends once a SAM is clearly established and the plantlet stage begins. After SAM formation, the protocorm can degenerate or enlarge forming a 'corm-like' structure, taking on varied forms (Veyret 1974; Batygina et al. 2003). The timing of root emergence also differs widely between species. Furthermore, the entire plantlet can remain subterranean for quite some time or elongate rapidly, emerges from the substratum and turns green (see Veyret 1974; Batygina and Andronova 2000; Batygina et al. 2003; Vinogradova and Andronova 2002). With such diverse morphogenetic changes, referring these varied forms as protocorms can be confusing.

For the ease of description and comparative evaluations from different published results, morphological stages of a protocorm or a plantlet in one's study should be clearly defined. The proposed stages of germination and protocorm development by Zettler and Hofer (1998) are useful schemes detailing changes in seeds during the course of germination and protocorm formation. Vinogradova and Andronova (2002) also recognized five shoot types to describe the complexity of shoots formed by the apical buds of protocorms. 

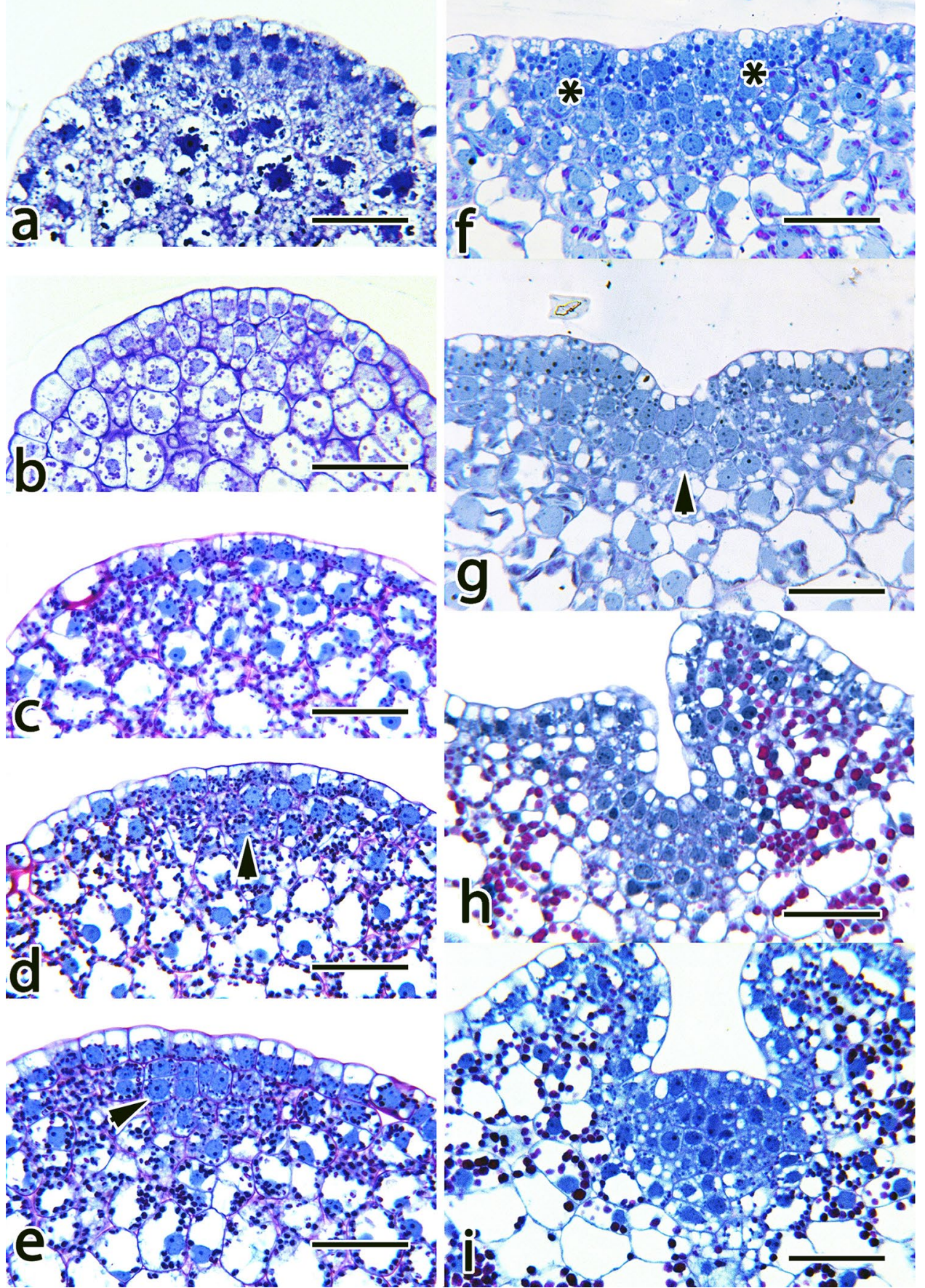

Fig. 1 Shows the structural ontogeny of a shoot apical meristem in Epidendrum ibaguense. a At the time of seed germination, the embryo cells have abundant storage product deposits. b Within 96 h, storage products have been mobilized and cells are becoming vacuolated; judging from the cell profile of the apical layer, mitotic divisions have begun. c Approximately 7 days after germination, protocorms start to turn green, plastids become abundant with starch within protocorm cells. Protocorm cells at the future shoot pole, albeit smaller, have similar cytological features. $\mathbf{d}$ Soon after, future shoot meristem cells (arrowhead) can be identified as they are smaller in size and with a large nucleus to cytoplasm ratio. e The SAM initials (arrowhead) take on a square-shape and starch granules become less abundant. These features clearly mark the structural identity of SAM cells. f The SAM increases in size and starch granules remain less abundant when compare to the rest of the protocorm cells. In the peripheral region of the SAM, the cells (Asterisk) start to expand. $\mathbf{g}$ Continual expansion of peripheral meristem cells result in the formation of a protrusion; this results in the formation of a 'dimple' with the SAM cells (arrowhead) located at the depression. $\mathbf{h}$ The SAM continues to grow in size, surrounded by a developing leaf primordium. i The SAM in a mature plantlet takes on a slightly domed-shaped structure, forming leaf primordia at a regular interval. All scale bar $=50 \mu \mathrm{m}$ 


\section{Protocorms as explants for micropropagation and transformation studies}

In a micropropagation system, initiating mitotic activities of an explant and generating cells with 'organogenic' or 'embryogenic' properties can be a challenge. The ability of apical protocorm cells to divide make them ideal explants for micropropagation and transformation studies. Rapid divisions occur 'naturally' at the meristematic zone allowing for better responses to exogenously applied plant growth regulators. Protocorm cells still retain 'embryogenic' properties, under appropriate in vitro culture conditions. Cells at the apical end can give rise to protocorm-like bodies (PLBs) directly from the surface of protocorms or indirectly through the formation of organogenic calli. The structural organization and developmental properties of PLBs are similar to protocorms in general. PLBs are considered as 'somatic embryos' of orchids. Lee et al. (2013) demonstrated that during PLB formation, there is a transient formation of storage proteins within PLB cells. This clearly indicates that PLBs retain features of zygotic embryo development, albeit transient in nature. In an in vitro environment, PLBs quickly "germinate" and function as protocorms, giving rise to plantlets.

Protocols utilizing protocorms for further micropropagation purposes are readily available in the literature (see reviews by Chugh et al. 2009; Teixeira da Silva 2013). Continual optimization of protocols such as thin section techniques (Teixeira da Silva 2013) and new approaches such as mass culture via bioreactor (Park et al. 2000) will be key to both commercialization and conservation of orchids. Descriptive information concerning PLB initiation from different explants is available in the literature, e.g. Paek et al. (2011); however, mechanistic processes regulating PLB formation are still lacking. Further studies will provide needed information on how the process of PLB regeneration is regulated.

Protocorms and PLBs are excellent explants for transformation studies (Hossain et al. 2013). Plant transformation technologies augment conventional breeding program. Due to the long generation time of orchids, transformation may reduce the time needed to produce a desirable trait. The key event in any transformation protocol is the ability of explants to regenerate after transformation. The ability for protocorms or protocorm sections to generate PLBs, make them ideal candidates for transformation studies. Successes are now reported regularly in the literature using protocorms and PLBs as explants (Phlaetita et al. 2015). One can expect rapid progress in this area of research in the near future.

\section{Protocorm explants can generate polyploidy plants}

Successful polyploid induction can improve plant characteristics. For orchids, polypoid production can improve floral or growth characteristics (Chen et al. 2011; Miguel and Leonhardt 2011). In Vanda, embryo cells are diploid maintaining a $2 \mathrm{C}$ complement of DNA; however, upon in vitro culture, up to $32 \mathrm{C}$ DNA content can be observed in some protocorm cells (Lim and Loh 2003). Chen et al. (2009; 2011) took advantage of the endopolyploidy properties of Phalaenopsis protocorm in which basal protocorm cells have a DNA content ranging from 2 to $8 \mathrm{C}$. Through regeneration of PLBs from protocorm thin sections and subsequent selection, polyploid plants can be identified and propagated (Chen et al. 2009; 2011).

Due to the small size and the exposed meristematic surface of protocorms and PLBs, polyploid plants can also be generated using anti-microtubule agents such as colchicine and oryzalin (Miguel and Leonhardt 2011; Chung et al. 2014). After treating with these anti-microtubule agents, followed by selection protocols, desirable polyploid plants can be generated, multiplied and maintained (Miguel and Leonhardt 2011; Chung et al. 2014).

\section{Conclusions and future perspectives}

Although it is minute in size, orchid embryo has carefully planned developmental programs ensuring successful symbiotic seed germination in their natural habitats. The outcome of embryo development is to generate a protocorm which has a unique structural designed for mycorrhizal establishment and a goal to form a shoot apical meristem for plantlet establishment.

At present, successes have been recorded for asymbiotic and symbiotic germination of seeds and micropropagation and transformation studies using protocorms (Chugh et al. 2009; Teixeira da Silva 2013; Lee and Yeung 2017). Many protocols are available which will aid to maintain and propagate important orchid species for further conservation purposes. In recent years, genomic information is becoming available for key commercial species, e.g. Cai et al. (2015), Niu et al. (2016), and Zhang et al. (2016). These studies will provide important data bases to decipher further molecular genetic information. In addition to taking advantage of this information, it is important to combine other approaches such as physiological, biochemical and cell biological methods in studying the seed and protocorm biology in order to gain a comprehensive picture of the entire process.

It is clear from this overview that much more information is needed. Many questions remain. From a developmental biology point of view, orchid embryo and protocorm are excellent and exciting experimental 
systems for plant biology research. Chances are, we will learn new regulatory mechanisms which will provide new perspectives to plant biology as a whole.

\section{Acknowledgements}

The author thanks Professor C.C. Chinnappa for the critical reading of the manuscript. This research was supported by Discovery grants from the Natural Sciences and Engineering Research Council of Canada to E. C. Yeung.

Dedicated to the memory of Professor lan M. Sussex.

\section{Competing interests}

The author declares that he has no competing interests.

\section{Availability of data and materials}

Not applicable.

\section{Ethics approval and consent to participate}

Not applicable.

\section{Funding}

Not applicable.

\section{Publisher's Note}

Springer Nature remains neutral with regard to jurisdictional claims in published maps and institutional affiliations.

Received: 23 May 2017 Accepted: 24 July 2017

Published online: 04 August 2017

\section{References}

Angelovici R, Fait A, Fernie AR, Galili G (2011) A seed high-lysine trait is negatively associated with the TCA cycle and slows down Arabidopsis seed germination. New Phytol 189:148-159

Arditti J (1992) Fundamentals of orchid biology. Wiley, New York

Arditti J, Ghani AKA (2000) Numerical and physical properties of orchid seeds and their biological implications. New Phytol 145:367-421

Arekal GD, Karanth KA (1981) The embryology of Epipogium roseum (Orchidaceae). Plant Syst Evol 138:1-7

Batygina TB, Andronova EV (2000) The orchid protocorm: an opinion. In: Muk erji K (ed) Glimpses in botany. APH Publishing Corporation, New Delhi

Batygina TB, Bragina EA, Vasilyeva VE (2003) The reproductive system and germination in orchids. Acta Biol Craco Ser Bot 45:21-34

Bouché-Pillon S, Fleurat-Lessard P, Serrano R, Bonnemain J-L (1994) Asymmetric distribution of the plasma-membrane H+-ATPase in embryos of Vicia faba L. with special reference to transfer cells. Planta 193:392-397

Cai J, Liu X, Vanneste K, Proost S, Tsai WC, Liu KW, Chen LJ, He Y, Xu Q, Bian C et al (2015) The genome sequence of the orchid Phalaenopsis equestris. Nat Genet 47:65-72

Chen WH, Tang CY, Kao YL (2009) Ploidy doubling by in vitro culture of excised protocorms or protocorm-like bodies in Phalaenopsis species. Plant Cell Tissue Organ Cult 98:229-238

Chen W-H, Kao Y-L, Tang C-Y, Lean G-T (2011) Endopolyploidy in Phalaenopsis orchids and its application in polyploid breeding. In: Chen W-H, Chen $\mathrm{H}-\mathrm{H}$ (eds) Orchid biotechnology II. World Scientific Publishing Co Ltd, Singapore

Chen JC, Wei MJ, Fang SC (2016) Expression analysis of fertilization/early embryogenesis-associated genes in Phalaenopsis orchids. Plant Signal Behav 11:e1237331

Chugh S, Guha S, Rao IU (2009) Micropropagation of orchids: a review on the potential of different explants. Sci Hortic 122:507-520

Chung MY, Kim CY, Min JS, Lee DJ, Naing AH, Chung JD, Kim CK (2014) In vitro induction of tetraploids in an interspecific hybrid of Calanthe (Calanthe discolor X Calanthe sieboldii) through colchicine and oryzalin treatments. Plant Biotechnol Rep 8:251-257
Clements MA (1999) Embryology. In: Pridgeon AM, Cribb PJ, Chase MW, Rasmussen FN (eds) Genera Orchidacearum, Vol. 1, General introduction, Apostasioideae, Cyripedioideae. Oxford University Press, Oxford

Cocucci AE, Jensen WA (1969) Orchid embryology: the mature megagametophyte of Epidendrum scutella following fertilization. Am J Bot 56:629-640

Colville L, Marks TR, Pritchard HW, Custodio CC, Machado-Neto NB (2016) Development of a reliable GC-MS method for fatty acid profiling using direct transesterification of minimal quantities of microscopic orchid seeds. Seed Sci Res 26:84-91

Dressler RL (1993) Phylogeny and classification of the orchid family. Cambridge University Press, Cambridge

Dure LS III (1979) Role of stored messenger RNA in late embryo development and germination. In: Rubenstein I, Phillips RL, Green CE, Gengenbach BG (eds) The plant seed. Academic Press, New York

Dure L (1985) Embryogenesis and gene expression during seed formation. Oxf Survey Plant Mol Cell Biol 2:179-197

Emery RJN, Atkins CA (2006) Cytokinins and seed development. In: Basra AS (ed) Seed science and technology: trends and advances. Haworth Press Inc., Binghamton

Fang SC, Chen JC, Wei MJ (2016) Protocorms and protocorm-like bodies are molecularly distinct from zygotic embryonic tissues in Phalaenopsis aphrodite. Plant Physiol 171:2682-2700

Feder N, O'Brien TP (1968) Plant microtechnique: some principles and new methods. Am J Bot 55:123-142

Fochi V, Chitarra W, Kohler A, Voyron S, Singan VR, Lindquist EA, Barry KW, Girlanda M, Grigoriev IV, Martin F et al (2017) Fungal and plant gene expression in the Tulasnella calospora-Serapias vomeracea symbiosis provides clues about N pathways in orchid mycorrhizas. New Phytol 213:365-379

Garciarrubio A, Legaria JP, Covarrubias AA (1997) Abscisic acid inhibits germination of mature Arabidopsis seeds by limiting the availability of energy and nutrients. Planta 203:182-187

Goldberg RB, De Paiva G, Yadegari R (1994) Plant embryogenesis: zygote to seed. Science 266:605-614

Graham IA (2008) Seed storage oil mobilization. Annu Rev Plant Biol 59:115-142

Harrison CR (1977) Ultrastructural and histochemical changes during the germination of Cattleya aurantiaca (Orchidaceae). Bot Gaz 138:41-45

Holdsworth MJ, Bentsink L, Soppe WJJ (2008) Molecular networks regulating Arabidopsis seed maturation, after-ripening, dormancy and germination. New Phytol 179:33-54

Hossain MM, Kant R, Van PT, Winarto B, Zeng S-J, Teixeira da Silva JA (2013) The application of biotechnology to orchids. Crit Rev Plant Sci 32:69-139

Huang BO Ye XL, Yeung EC, Zee SY (1998) Embryology of Cymbidium sinense: the microtubule organization of early embryos. Ann Bot 81:741-750

Johansen DA (1950) Plant embryology. Chronica Botanica, Waltham

Johnson TR, Stewart SL, Dutra D, Kane ME, Richardson L (2007) Asymbiotic and symbiotic seed germination of Eulophia alta (Orchidaceae) - preliminary evidence for the symbiotic culture advantage. Plant Cell Tissue Organ Cult 90:313-323

Kauth PJ, Dutra D, Johnson TR, Stewart SL, Kane ME, Vendrame W (2008) Techniques and applications of in vitro orchid seed germination. In: Teixeira da Silva JA (ed) Floriculture, ornamental and plant biotechnology: advances and topical Issues (Vol. V). Global Science Books, Ltd., Isleworth

Kawashima T, Goldberg RB (2010) The suspensor: not just suspending the embryo. Trends Plant Sci 15:23-30

Knudson L (1922) Non-symbiotic germination of orchid seeds. Bot Gaz $73: 1-25$

Kodahl N, Johansen BB, Rasmussen FN (2015) The embryo sac of Vanilla imperialis (Orchidaceae) is six-nucleate, and double fertilization and formation of endosperm are not observed. Linn Soc Bot J 177:202-213

Lackie S, Yeung EC (1996) Zygotic embryo development in Daucus carota. Can J Bot 74:990-998

Laux T, Würschum T, Breuninger H (2004) Genetic regulation of embryonic pattern formation. Plant Cell 16(Suppl):S190-S202

Law SK, Yeung EC (1993) Embryology of Cypripedium passerimum (Orchidaceae): ovule development. Lindleyana 8:139-147

Lee YI (2011) In vitro culture and germination of terrestrial Asian orchid seeds. In: Thorpe TA, Yeung EC (eds) Plant embryo culture: methods and protocols. Humana Press, New York 
Lee Y-I, Yeung EC (2010) The osmotic property and fluorescent tracer movement of developing orchid embryos of Phaius tankervilliae (Aiton) BI. Sex Plant Reprod 23:337-341

Lee Y-I, Yeung EC (eds) (2017) Orchid propagation: from laboratories to greenhouses: methods and protocols. Springer, New York [in press]

Lee Y-I, Yeung EC, Lee N, Chung M-C (2006) Embryo development in the lady's slipper orchid, Paphiopedilum delenatii with emphases on the ultrastructure of the suspensor. Ann Bot 98:1311-1319

Lee Y-I, Yeung EC, Chung M-C (2007a) Embryo development of orchids. In: Chen W-H, Chen H-H (eds) Orchid biotechnology. World Scientific Publishing Co. Pte. Ltd., Singapore

Lee YI, Lu CF, Chung MC, Yeung EC, Lee N (2007b) Developmental changes in endogenous abscisic acid concentrations and asymbiotic seed germination of a terrestrial orchid, Calanthe tricarinata Lindl. J Am Soc Hortic Sci 132:246-252

Lee Y-I, Yeung EC, Lee N, Chung MC (2008) Embryology of Phalaenopsis amabilis var. formosa: embryo development. Bot Stud 49:139-146

Lee Y-I, Hsu S-T, Yeung EC (2013) Orchid protocorm-like bodies are somatic embryos. Am J Bot 100:2121-2131

Lee Y-I, Chung M-C, Yeung EC, Lee N (2015) Dynamic distribution and the role of abscisic acid during seed development of a lady's slipper orchid, Cypripedium formosanum. Ann Bot 116:403-411

Leroux GL, Barabe D, Vieh J (1997) Morphogenesis of the protocorm of Cypripedium acaule (Orchidaceae). Plant Syst Evol 205:53-72

Lim WL, Loh CS (2003) Endopolyploidy in Vanda miss Joaquim (Orchidaceae). New Phytol 159:279-287

Lin HY, Chen JC, Wei MJ, Lien YC, Li HH, Ko SS, Liu ZH, Fang SC (2014) Genomewide annotation, expression profiling, and protein interaction studies of the core cell-cycle genes in Phalaenopsis aphrodite. Plant Mol Biol 84:203-226

Linden B (1992) Two new methods for pretreatment of seeds of Northern orchids to improve germination in axenic culture. Ann Bot Fenn 29:305-313

Ling H, Zeng X, Guo S (2016) Functional insights into the late embryogenesis abundant (LEA) protein family from Dendrobium officinale (Orchidaceae) using an Escherichia coli system. Sci Rep 6:39693

Liu H, Luo Y, Liu H (2010) Studies of mycorrhizal fungi of Chinese orchids and their role in orchid conservation in China - a review. Bot Rev 76:241-262

Lopes MA, Larkins BA (1993) Endosperm origin, development, and function. Plant Cell 5:1383-1399

López-Chávez MY, Guillén-Navarro K, Bertolini V, Encarnación S, HernándezOrtiz M, Sánchez-Moreno I, Damon A (2016) Proteomic and morphometric study of the in vitro interaction between Oncidium sphacelatum Lindl. (Orchidaceae) and Thanatephorus sp. RG26 (Ceratobasidiaceae). Mycorrhiza 26:353-365

Lopez-Villalobos A, Lopez-Quiroz AA, Yeung EC (2016) Asymmetric cell division in the zygote of flowering plants: the continuing polarized event of embryo sac development. In: Rose RJ (ed) Molecular cell biology of the growth and differentiation of plant cells. CRC Press, Boca Raton

Masuhara G, Katsuya K (1994) In situ and in vitro specificity between Rhizoctonia spp. and Spiranthes sinensis (Persoon) Ames. var. amoena (M. Bieberstein) Hara (Orchidaceae). New Phytol 127:711-718

Miguel TP, Leonhardt KW (2011) In vitro polyploid induction of orchids using oryzalin. Sci Hortic 130:314-319

Miyoshi K, Mii M (1988) Ultrasonic treatment for enhancing seed germination of terrestrial orchid, Calanthe discolor, in asymbiotic culture. Sci Hortic 35:127-130

Molvray M, Chase MW (1999) Seed morphology. In: Pridgeon AM, Cribb PJ, Chase MW, Rasmussen FN (eds) Genera Orchidacearum Volume 1 General introduction, Apostasioideae, Cypripedioideae. Oxford University Press Inc., New York

Mweetwa AM, Welbaum GE, Tay D (2008) Effects of development, temperature, and calcium hypochlorite treatment on in vitro germinability of Phalaenopsis seeds. Sci Hortic 117:257-262

Nambara E, Okamoto M, Tatematsu K, Yano R, Seo M, Kamiya Y (2010) Abscisic acid and the control of seed dormancy and germination. Seed Sci Res 20:55-67

Nardmann J, Werr W (2006) The shoot stem cell niche in angiosperms: expression patterns of WUS orthologues in rice and maize imply major modifications in the course of mono- and dicot evolution. Mol Biol Evol 23:2492-2504
Natesh S, Rau MA (1984) The embryo. In: Johri BM (ed) Embryology of angiosperms. Springer-Verlag, Berlin

Nishimura G (1991) Comparative morphology of cotyledonous orchid seedlings. Lindleyana 6:140-146

Niu SC, Xu Q, Zhang GQ, Zhang YQ, Tsai WC, Hsu JL, Liang CK, Luo YB, Liu Z (2016) De novo transcriptome assembly databases for the butterfly orchid Phalaenopsis equestris. Sci Data 3:160083

Novak SD, Luna LJ, Gamage RN (2014) Role of auxin in orchid development. Plant Signal Behav 9:2972277-1

O'Brien TP, McCully ME (1981) The study of plant structure: principles and selected methods. Termarcarphi Pty, Ltd, Melbourne

O'Brien TP, Feder N, McCully ME (1964) Poly-chromatic staining of plant cell walls by toluidine blue O. Protoplasma 59:368-373

Paek KY, Hahn EJ, Park SY (2011) Micropropagation of Phalaenopsis orchids via protocorms and protocorm-like bodies. Methods Mol Biol 710:293-306

Park SY, Murthy HN, Yoeup PK (2000) Mass multiplication of protocorm-like bodies using bioreactor system and subsequent plant regeneration in Phalaenopsis. Plant Cell Tissue Organ Cult 63:67-72

Phlaetita W, Chin DP, Otanga NV, Nakamura I, Mii M (2015) High efficiency Agrobacterium-mediated transformation of Dendrobium orchid using protocorms as a target material. Plant Biotech 32:323-327

Raghavan V (1997) Molecular embryology of flowering plants. Cambridge University Press, Cambridge

Raghavan V, Goh CJ (1994) DNA synthesis and mRNA accumulation during germination of embryos of the orchid Spathoglottis plicata. Protoplasma 183:137-147

Rasmussen HN (1990) Cell differentiation and mycorrhizal infection in Dactylorhiza majalis (Rchb. F.) Hunt \& Summerh. (Orchidaceae) during germination in vitro. New Phytol 116:137-143

Rasmussen HN (1995) Terrestrial orchids: from seed to mycotrophic plant. Cambridge University Press, Cambridge

Rodkiewicz B, Fyk B, Szczuka E (1994) Chlorophyll and cutin in early embryogenesis in Capsella, Arabidopsis, and Stellaria investigated by fluorescence microscopy. Sex Plant Reprod 7:287-289

Russell SD (1985) Preferential fertilization in Plumbago: ultrastructural evidence for gamete-level recognition in an angiosperm. Proc Nat Acad Sci USA 82:6129-6132

Sano N, Permana H, Kumada R, Shinozaki Y, Tanabata T, Yamada T, Hirasawa T, Kanekatsu M (2012) Proteomic analysis of embryonic proteins synthesized from long-lived mRNAs during germination of rice seeds. Plant Cell Physiol 53:687-698

Schwallier R, Bhoopalan V, Blackman S (2011) The influence of seed maturation on desiccation tolerance in Phalaenopsis amabilis hybrids. Sci Hortic 128:136-140

Smith DL (1972) Staining and osmotic properties of young gametophytes of Polypodium vulgare $L$. and their bearing on rhizoid function. Protoplasma 74:465-479

Smith SE, Read DJ (2008) Mycorrhizal symbiosis. Academic Press, New York

Stoutamire WP (1983) Early growth in North American terrestrial orchid seedlings. In: Plaxton EH (ed), North American terrestrial orchids symposium II, proceedings and lectures, 14-24. Michigan Orchid Society, Livonia, Ml

Sussex IM (1989) Developmental programming of the shoot meristem. Cell $56: 225-229$

Swamy BGL (1947) On the life-history of Vanilla planifolia. Bot Gaz 108:449-459

Swamy BGL (1949) Embryological studies in the Orchidaceae. II. Embryology. Am Midl Nat 41:202-232

Taylor JS, Blackman SJ, Yeung EC (1982) Hormonal and structural aspects of fruit development in the orchid, Epidendrum. J Exp Bot 33:495-505

Teixeira da Silva JA (2013) Orchids: advances in tissue culture, genetics, phytochemistry and transgenic biotechnology. Floric Ornam Biotechnol $7: 1-52$

Tian HQ, Zhang ZJ, Russell SD (2001) Sperm dimorphism in Nicotiana tabacum L. Sex Plant Reprod 14:123-125

Ueda M, Laux T (2012) The origin of the plant body axis. Curr Opin Plant Biol 15:578-584

Valadares RB, Perotto S, Santos EC, Lambais MR (2014) Proteome changes in Oncidium sphacelatum (Orchidaceae) at different trophic stages of symbiotic germination. Mycorrhiza 24:349-360

Van der Kinderen G (1987) Abscisic acid in terrestrial orchid seeds: a possible impact on their germination. Lindleyana 2:84-87 
van der Pilj L, Dodson CH (1966) Orchid flowers: their pollination and evolution. University of Miami Press, Coral Gables

Veyret Y (1969) La structure des semences des Orchidaceae et leur aptitude à la germination in vitro en cultures pures. In: Travaux du Laboratorie de la Jaysinia, vol 3. Laboratorie de Biologie Végétale du Muséum, Paris, pp 89-98

Veyret Y (1974) Development of the embryo and the young seedling stages of orchids. In: Withner CL (ed) The orchids: scientific studies. Wiley, New York, pp 223-265

Vijayaraghavan MR, Prabhakar K (1984) The endosperm. In: Johri BM (ed) Embryology of angiosperms. Springer, Berlin

Vinogradova TN, Andronova EV (2002) Development of orchid seeds and seedlings. In: Kull T, Arditti J (eds) Orchid biology: reviews and perspectives, VIII. Kluwer Academic Publishers, Dordrecht

Wabnik K, Robert HS, Smith RS, Friml J (2013) Modeling framework for the establishment of the apical-basal embryonic axis in plants. Curr Biol 23:2513-2518

Weterings K, Russell SD (2004) Experimental analysis of the fertilization process. Plant Cell 16:S107-S118

Wright M, Guest D, Cross R (2005) Development of mycorrhiza association in Caladenia tentaculata. Selbyana 26:114-124

Xu N, Bewley JD (1995) The role of abscisic acid in germination, storage protein synthesis and desiccation tolerance in alfalfa (Medicago sativa L.) seeds, as shown by inhibition of its synthesis by fluridone during development. J Exp Bot 46:687-694

Yam TW, Yeung EC, Ye X-L, Zee S-Y, Arditti J (2002) Embryology-seeds. In: Arditti J, Kull T (eds) Orchid biology: reviews and perspectives VIII. Kluwer Academic Publishers, Dordrecht

Yamazaki J, Miyoshi K (2006) In vitro asymbiotic germination of immature seed and formation of protocorm by Cephalanthera falcate (Orchidaceae). Ann Bot 98:1197-1206

Yang CK, Lee YI (2014) The seed development of a mycoheterotrophic orchid, Cyrtosia javanica Blume. Bot Stud 55:44
Ye XL, Zee SY, Yeung EC (1997) Suspensor development in the nun orchid, Phaius tankervilliae. Int J Plant Sci 158:704-712

Ye X-L, Yeung EC, Zee S-Y (2002) Sperm movement during double fertilization of a flowering plant, Phaius tankervilliae. Planta 215:60-66

Yeung EC, Law SK (1992) Embryology of Calypso bulbosa. II. Embryo development. Can J Bot 70:461-468

Yeung EC, Law SK (1997) Ovule development. In: Arditti J, Pridgeon AM (eds) Orchid biology: reviews and perspectives VII. Kluwer, Dordrecht

Yeung EC, Meinke DW (1993) Embryogenesis in angiosperms: development of the suspensor. Plant Cell 5:1371-1381

Yeung EC, Zee SY, Ye XL (1996) Embryology of Cymbidium sinense: embryo development. Ann Bot 78:105-110

Zettler LW, Hofer CJ (1998) Propagation of the little club-spur orchid (Platanthera clavellate) by symbiotic seed germination and its ecological implications. Environ Exp Bot 39:189-195

Zhang XS, O'Neill SD (1993) Ovary and gametophyte are coordinately regulated by auxin and ethylene following pollination. Plant Cell 5:403-418

Zhao M-M, Zhang G, Zhang D-W, Hsiao Y-Y, Guo S-X (2013) ESTs analysis reveals putative genes involved in symbiotic seed germination in Dendrobium officinale. PloS One 8:e72705

Zou J, Abrams GD, Barton DL, Taylor DC, Pomeroy MK, Abrams SR (1995) Induction of lipid and oleosin biosynthesis by (+)-Abscisic acid and its metabolites in microspore-derived embryos of Brassica napus L.cv Reston (Biological responses in the presence of 8[prime]-Hydroxyabscisic acid). Plant Physiol 108(2):563-571

Zhang GQ, Xu Q, Bian C, Tsai WC, Yeh CM, Liu KW, Yoshida K, Zhang LS, Chang SB, Chen F, Shi Y, Su YY, Zhang YQ, Chen LJ, Yin Y, Lin M, Huang H, Deng H, Wang ZW, Zhu SL, Zhao X, Deng C, Niu SC, Huang J, Wang M, Liu GH, Yang HJ, Xiao XJ, Hsiao YY, Wu WL, Chen YY, Mitsuda N, Ohme-Takagi M, Luo YB, Van de Peer Y, Liu ZJ (2016) The Dendrobium catenatum Lindl. genome sequence provides insights into polysaccharide synthase, floral development and adaptive evolution. Sci Rep 6:19029. doi:10.1038/ srep19029

\section{Submit your manuscript to a SpringerOpen ${ }^{\odot}$ journal and benefit from:}

- Convenient online submission

- Rigorous peer review

- Open access: articles freely available online

- High visibility within the field

- Retaining the copyright to your article

Submit your next manuscript at $\boldsymbol{\nabla}$ springeropen.com 